\title{
Developing a healthy food based on concentrated must
}

\author{
Carolina Coria $^{1, a}$, María José Molina ${ }^{2}$, Carlos Bustamante $^{2}$, and Carla Aruani ${ }^{1}$ \\ ${ }^{1}$ Instituto Nacional de Vitivinicultura, Departamento de Estudios Enológicos y Sensoriales, (5500) San Martín 430, \\ Mendoza, Argentina \\ ${ }^{2}$ Nutrición para la Vida, Nutrición y cocina Ortomolecular, (5507) Chaco 1347, Luján de Cuyo, Mendoza, Argentina
}

\begin{abstract}
Considering the characteristics and charitable qualities of the Grape Juice Concentrate (JUC) as a nutrient food, and the poor eating habits that our actual society suffers, it was thought for this work the application of simple tools and practices enabling of benefit to health through the use of regional and natural products. The objective of this research was to formulate and develop a health food of a stick type to JUC based. Two types of "stick" with different formulations, which were assessed by affective sensory tests regarding the acceptability and the degree of preference of these, were developed. For sensory evaluation, panel of untrained judges randomly selected was settled. From the evaluated, there were not significant differences between the sticks acceptance, this paper proposes to continue improving formulations JUC based product, so as to have in the future with a highly nutritious product that can be incorporated in the diet of an ordinary citizen and Food Assistance Programs developed at country level.
\end{abstract}

\section{Introduction}

In Argentina the production of "Grape Juice Concentrate" (JUC) plays an important role, because it is a net exporter regional economy of high international competitiveness. Their marketing focuses on the foreign market, exporting about $95 \%$ of the production, being its main buyer USA.

Currently the market JUC acts as a regulatory tool in the wine trade deal, allowing cushion the fall in the price of wine, promoting the performance of our winemaking.

In the last years, the global financial crisis has led to the Argentine wine sector in search of additional measures that promote JUC marketing in the domestic market [1].

Given the need to encourage the production of JUC in our country and strengthening its marketing, noting the domestic market as an alternative of significance to complement exports, it was thought to diversify its use as grape product, using it as a nutritional and healthy alternative for the Argentina population.

Nowadays, the low quality diet of Argentineans is an issue of the agenda and concern at the country level. The diet is based on poor dietary practices, which remain essential nutrients such as iron, calcium, vitamins A and $\mathrm{C}$ mainly fiber, omegas 3 and 9 , folic acid, among others; or, excess saturated fat, calories, sodium and sugars are added. These deficiencies in the nutritional quality translate into health problems linked into a poor growth and development or, in the other side overweight and obesity that affects one of the three children and one of two adults [2].

Considering on the one hand the features and beneficial qualities that the JUC as nutrient food and the need to

\footnotetext{
${ }^{a}$ Corresponding author: carolinacoria@inv.gov . ar
}

diversify their use, and the other hand the poor eating habits, it was thought in the application of simple tools and practices that allow provide the use of regional and natural products on benefit to health.

To do this, two products were developed based on concentrated grape type "stick". For the formulation of the "stick" proper nutrition and orthomolecular holistic cooking techniques were applied. In this paper seeks to innovate, not just developing a different product, but also making maximum use of local produce, giving to the final product nutritional relevance.

\subsection{Grape juice concentrate}

The JUC is defined as the product obtained from grape must at various degrees of concentration by vacuum thermal processes or outdoors without suffering an appreciable browning [3].

This juice, commonly called "must" is very important because it works as an additive for most consumer products. Thanks to its natural qualities, high in sugars and neutral flavor, is used for the manufacture of baby products, candies, jellies, jams, pharmaceuticals, fruits in syrup, etc.

\subsection{Orthomolecular nutrition and cooking}

The orthomolecular concept is defined as "ortho" the task of correcting and / or dose and "molecular" linking the nutrients corrective properties to preserve health and treat disease. This task properly managed the optimum amount of molecules necessary for the body such as proteins, vitamins, minerals, fatty acids, etc. [4].

This is an Open Access article distributed under the terms of the Creative Commons Attribution License 4.0, which permits unrestricted use, distribution, and reproduction in any medium, provided the original work is properly cited. 
Table 1. Formulations obtained for "bars".

\begin{tabular}{|l|c|c|}
\hline \multirow{2}{*}{ Ingredients } & "stick A" & "stick B" \\
\cline { 2 - 3 } chickp ea & g/25 stick & g/25 stick \\
white corn & - & 600 \\
walnut & 150 & 700 \\
chia & 35 & 150 \\
sunflower & 150 & 35 \\
millet & 50 & 150 \\
raisins & 150 & 150 \\
birdseed & - & 120 \\
rice & 600 & - \\
lentils & 600 & - \\
\hline JUC & $400 \mathrm{cc}$. & $400 \mathrm{cc}$ \\
\hline
\end{tabular}

Orthomolecular kitchen is that which start from the knowledge of the essential nutrient characteristics of plant and animal foods, ensures the preparation thereof, balanced conservation of its beneficial properties, preventing the loss of nutrients in the preparation and cooking.

\section{Material and methods}

\subsection{Features food based on must concentrate}

Before considering the ingredients and composition of the "stick", a number of features that they should meet were defined: a) provide the necessary nutrients for a proper diet; b) contain as base at preparation the JUC, used to sweeten and to hydrate the other ingredients; c) selecting ingredients for easy acquisition, considering regional products, and relative low cost; d) simple and lowest cost processing; e) nice flavor to stimulate the consumption of "stick"; f) size of the "stick" should be practical for consumption as snack and finally g) consistency and attractive packaging that allow the proper conservation of "stick".

\subsubsection{Ingredient selection, composition and processing}

To select the ingredients, relevant documents about the nutritional value $[5,6]$ and the performance thereof is checked after processing and cooking [7,8]. Accordingly, it was decided to use seeds, legumes, cereals, and nuts together with the JUC, that in addition to its qualities as a nutrient food, can sweeten, highlighting and unifying flavor (Table 1).

The elaboration of the "stick" took place in a pastry that besides the traditional cuisine, develops own techniques of orthomolecular holistic cuisine. As for the ingredients, the "stick A" was prepared with rice and lentil basis, which were activated, that is hydrated to facilitate digestion and easily absorb vitamins and minerals present therein. Like bars of commercial size were then molded and led to the oven for final assembly. For the "stick B" was used gram and white corn as basis, both activated, but in contrast of the "stick A", these ingredients were cooked previously molded and assembly. Both "sticks" in

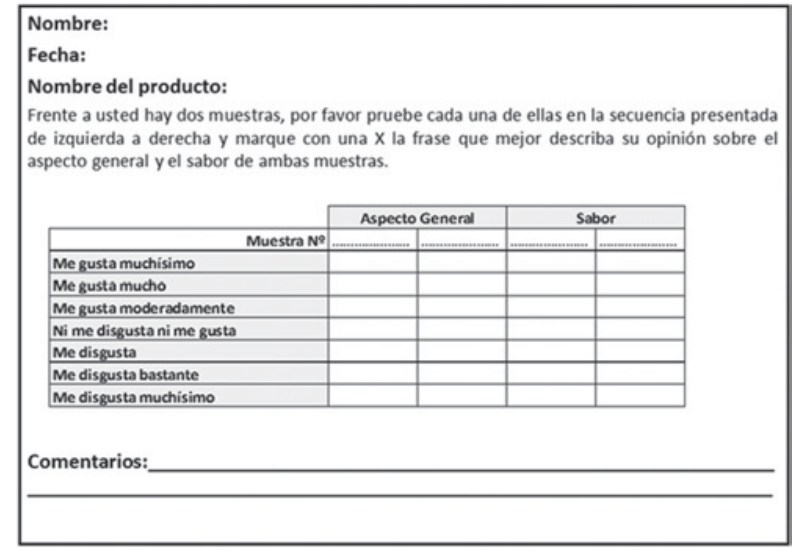

Figure 1. Tab used for acceptance testing.

their formulations lead millet, which was also activated before being incorporated into the preparation. The rest of the ingredients such as seeds, nuts and dehydrated, were incorporated directly.

The star ingredient of the developed formulations was the JUC. This additive was used to sweeten, amalgamate and hydrate the remaining constituents of the plant kingdom, which together deliver a nutrient mixture of excellent quality, to preserve their physiological state.

Once the "stick" molded were taken to the oven, then cooled outdoor and when they were free of moisture were wrapped and coded for analysis by the affective panel.

\subsection{Sensory evaluation tests}

To evaluate the acceptability and preference of developed "sticks" affective sensory tests were performed. These tests were applied not only to assess if there are differences in acceptance and preference among the two developed sticks, but also to consider the comments of the panelists that allow making decisions that optimize and improve the final product looking. For this, a panel of untrained judges randomly selected that could represent in the first instance, potential consumers of the "sticks" was formed.

The sessions were conducted at the Laboratory for Sensory Analysis in the Department of Winemaking and Sensory Studies, National Institute of Viticulture. Samples were presented to panelists according to a complete experimental design, randomly encoded [9].

\subsubsection{Acceptability test}

Acceptability was assessed using a rating scale with seven levels, evaluating two attributes: general appearance and flavor (Fig. 1).

\subsubsection{Preference Test}

The degree of preference was measured by a paired test, where each panelist was indicated to select which of the "sticks" preferred, evaluating each product in its entirety requested. 
Table 2. Data and analysis test acceptability.

\begin{tabular}{|c|c|c|c|c|}
\hline \multirow[t]{2}{*}{ Panelists } & \multicolumn{2}{|c|}{ General Appearance } & \multicolumn{2}{|c|}{ Flavor } \\
\hline & stick A & stick B & stick A & stick B \\
\hline $\mathbf{1}$ & 6 & 5 & 5 & 4 \\
\hline 2 & 6 & 6 & 6 & 5 \\
\hline 3 & 6 & 4 & 5 & 4 \\
\hline 4 & 5 & 4 & 5 & 4 \\
\hline 5 & 6 & 4 & 6 & 5 \\
\hline 6 & 4 & 4 & 4 & 4 \\
\hline 7 & 5 & 4 & 5 & 4 \\
\hline 8 & 4 & 5 & 4 & 5 \\
\hline 9 & 7 & 6 & 6 & 5 \\
\hline 10 & 6 & 5 & 5 & 4 \\
\hline 11 & 6 & 6 & 6 & 5 \\
\hline 12 & 4 & 5 & 3 & 5 \\
\hline 13 & 5 & 4 & 6 & 3 \\
\hline 14 & 5 & 4 & 5 & 5 \\
\hline 15 & 5 & 6 & 5 & 6 \\
\hline 16 & 6 & 5 & 7 & 5 \\
\hline 17 & 4 & 5 & 4 & 6 \\
\hline 18 & 5 & 5 & 7 & 5 \\
\hline 19 & 5 & 6 & 5 & 6 \\
\hline 20 & 5 & 4 & 5 & 4 \\
\hline 21 & 4 & 4 & 4 & 5 \\
\hline 22 & 6 & 3 & 5 & 5 \\
\hline 23 & 5 & 6 & 5 & 6 \\
\hline 24 & 7 & 5 & 7 & 5 \\
\hline 25 & 4 & 4 & 5 & 6 \\
\hline 26 & 4 & 5 & 4 & 5 \\
\hline 27 & 6 & 5 & 6 & 5 \\
\hline 28 & 5 & 3 & 5 & 2 \\
\hline 29 & 6 & 6 & 5 & 6 \\
\hline 30 & 4 & 5 & 5 & 7 \\
\hline 31 & 4 & 5 & 4 & 6 \\
\hline 32 & 5 & 6 & 5 & 6 \\
\hline 33 & 5 & 4 & 6 & 4 \\
\hline 34 & 4 & 4 & 4 & 6 \\
\hline 35 & 5 & 5 & 5 & 6 \\
\hline 36 & 5 & 5 & 5 & 6 \\
\hline $\bar{x}$ & 5,11 & 4,78 & 5,11 & 5,00 \\
\hline $\mathbf{S}$ & $\mathbf{0 , 8 9}$ & $\mathbf{0 , 8 7}$ & 0,92 & 1,01 \\
\hline $\mathbf{N}$ & 36 & 36 & 36 & 36 \\
\hline Degree of & 70 & & 70 & \\
\hline $\begin{array}{c}\text { freedom } \mathrm{N}-2 \\
\text { critical value } t\end{array}$ & 108 & & 198 & \\
\hline value $\mathbf{t}$ & 0,076 & & 0,653 & \\
\hline
\end{tabular}

\section{Results and discussion}

\subsection{Acceptance test}

The results of this testing, as assessed by 36 panelists, are shown in Table 2 to see if the "sticks" were accepting panelists (translated into numerical scale), medium was determined $(\bar{x})$ and standard deviation $(\mathrm{S})$.

To verify the difference between the two, the value of $\mathrm{t}$ for an independent test, two-tailed, and a $5 \%$ probability $(0.05)$ was calculated.

The average acceptability of the sticks was close to 5 , value according to the hedonic scale, shows that both formulations like moderately.

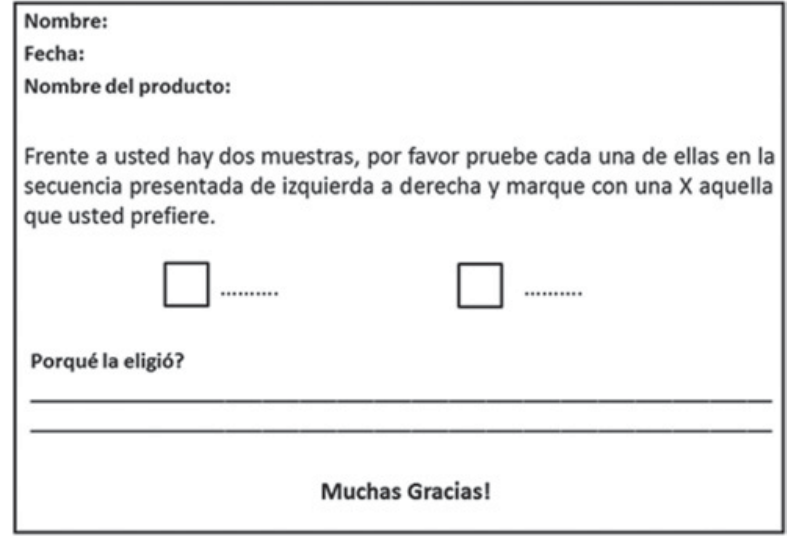

Figure 2. Tab used for paired preference test.

The critical value of $t$, according to statistics table [10], for $\mathrm{N}=70$, two-tailed, and $\mathrm{p}=0.05$, is 1.98 . The calculated value for both attributes to evaluate, was less than the critical $t$, therefore it is concluded that there are no significant differences in acceptance among both "sticks". And evaluated at the end of this study, they should rethink formulations to achieve a greater degree of acceptance.

\subsection{Preference test}

The degree of preference was measured using a paired test, two-tailed [11], establishing the null hypothesis, Ho, that there is no statistically significant preference between the two "sticks" to a level of significance of $5 \%$.

The results showed that 32 panelists from a total of 60 , preferred the sample B. From statistical table [12], the probability of preferring $\mathrm{B}, 32 / 60$, is $0.065(6.5 \%)$. This probability is high, so the Ho is accepted. For this test, we conclude that there is no preference of the panelists regarding one of the two "stick" in the study.

The main observations made by the panelists were: lack of compaction, indicating that much shelled and lost consistency in the mouth; the moisture level, which suggests that it should be smaller to achieve a crisp feel and / or crispy and increase sweetness to mask some vegetable flavorings that disharmony the final taste.

\section{Conclusions}

From the evaluated, this work proposes to continue improving product formulations based on JUC with the possibility to have to future with a highly nutritious and distinctive product that can be accepted and incorporated into the diet of an ordinary citizen and Food Assistance Programs developed at country level.

Going forward, we will seek that the product being attractive from the sensory stanpoint to the consumer, achieving its demand not only to know its nutritional benefits, also because they like and have a good reputation in massive group, evaluating it through the time. Moreover, the costs will be assessed to achieve the desired healthy food is acquired by any consumer that requires it.

The authors thank the staff of the National Institute of Viticulture and students of the University Juan Agustín Maza, for participating as panelists in sensory tests. 


\section{References}

[1] Ministerio de Agricultura, Ganadería y Pesca Dirección de Agroalimentos. Dirección Nacional de Procesos y Tecnologías. Subsecretaría de Agregado de Valor y Nuevas Tecnologías, El mercado del Jugo Concentrado de Uva, Informe de Coyuntura $N^{\circ} 2$, p.7. (2013)

[2] S. Britos, A. Saraví, N. Chichizola, F. Vilella, Buenas prácticas para una alimentación saludable de los argentinos. Facultad de Agronomía, Universidad de Buenos Aires, $1^{\mathrm{a}}$ ed., (2010)

[3] Instituto Nacional de Vitivinicultura, Ley General de Vinos N¹4.878, artículo 17, (1989)

[4] A. Odón, Congreso Nacional Mercuriados, Asociación Española de afectados por el mercurio de amalgamas dentales y otras situaciones, Valencia, España, (2009)

[5] O. Martinez Augustín, E. Martinez de Victoria Muñoz. Proteínas y péptidos en nutrición enteral. Nutrición Hospitalaria, España, 21 supl. 2, 1-14, (2006)
[6] M. M. Suarez López, A. Kizlansky y L. B. Lopez. Evaluación de la calidad de las proteínas en los alimentos calculando el escore de aminoácidos corregido por digestibilidad. Nutrición Hospitalaria, Argentina, 21(1):47-51, (2006)

[7] R.S. Harris y E. Karmas Nutritional evaluation of food processing AVI, 2 ${ }^{\mathrm{a}}$ Ed. Westport (1975)

[8] R.J. Priestley. Vitamins. Effects of heating on foodstuffs. Applied science publishers, Londres, 121-156, (1979)

[9] Andaluza Antonio, Tabla de Números Aleatorios, (1994)

[10] Fisher and Yates, Statistical Tables of Biological, Agricultural and Medical Research, Published by Longman Group Ltd., London

[11] M. O’Mahony, Food Science and Technology, M. Dekker, Inc., New York, (1986), p. 81

[12] E.B. Roessler et al., Journal of Food Science, 43, 940-947, (1978) 